\title{
Navigating 'Ethics in Practice': an Ethnographic Case Study with Young Women Living with HIV in Zambia
}

Mackworth-Young $\mathrm{CRS}^{1,2^{*}}$, Schneiders $\mathrm{ML}^{3}$, Wringe $\mathrm{A}^{4}$, Simwinga $\mathrm{M}^{2}$, Bond, $\mathrm{V}^{1,2}$.

1. Department of Global Health and Development, Faculty of Public Health and Policy, London School of Hygiene and Tropical Medicine, London, United Kingdom

2. Zambart, School of Public Health, University of Zambia, Lusaka, Zambia

3. Ethox Centre, Nuffield Department of Population Health, University of Oxford, United Kingdom

4. Department of Population Health, Faculty of Epidemiology and Population Health, London School of Hygiene and Tropical Medicine, London, United Kingdom

* Corresponding Author: Constance RS. Mackworth-Young

London School of Hygiene and Tropical Medicine,

15-17 Tavistock Place, London, WC1H 9SH, United Kingdom

Email: constance.mackworth-young1@1shtm.ac.uk

ORCiD: 0000-0002-9725-7931 


\title{
Navigating 'Ethics in Practice': an Ethnographic Case Study with Young Women Living with HIV in Zambia
}

\begin{abstract}
While 'procedural ethics' provides essential frameworks for governing global health research, reflecting on 'ethics in practice' offers important insights into addressing ethically important moments that arise in everyday research. Particularly for ethnographic research, renowned for it's fluid and spontaneous nature, engaging with 'ethics in practice' has the potential to enhance research practice within global health. We provide a case study for such reflexivity, exploring 'ethics in practice' of ethnographic research with middle-income young women living with HIV in Lusaka, Zambia. We explore the ethical issues arising from the layered interaction of the population (young women), the disease under investigation (HIV), the method of study (ethnographic), and the setting (Zambia, a lower middle income country). We describe how we navigated five key practical ethical tensions that arose, namely the psycho-emotional benefits of the research, the negotiated researcher-participant relationship, protecting participants' HIV status, confidentiality and data ownership, and researcher obligations after the end of the research. We exemplify reflexive engagement with 'ethics in practice' and suggest that engaging with ethics in this way can make important contributions towards developing more adequate ethical guidelines and research practice in global public health.
\end{abstract}

\section{Key words:}

Research ethics, HIV, Young adults, Ethnography, Zambia 


\section{Introduction}

A growing appreciation of the ethical complexities in conducting global health research has resulted in the development of increasingly nuanced ethical guidelines in recent decades (Office for Human Research Protections, 2018). Certain populations are deemed to be at potentially higher risk of encountering ethical issues, including young people (Nuffield, 2015), people living with HIV/AIDS (Hlongwa, 2016), and populations living in low-and-middle income countries (LMICs) (CIOMS, 2016). Additionally, there is widespread recognition that 'the emergent, dynamic and interactional nature of most qualitative research', including ethnographic methods, gives rise to a unique set of ethical considerations due to their intimate and longitudinal engagement with participants (Iphofen \& Tolich, 2018, p. 1). Yet outside the field of bioethics and beyond the regulatory phase of seeking ethical approval for a study, such ethical issues are rarely centre stage in discussions about global health research. In this paper we hope to foreground such a discussion, at the intersections of an ethically salient population, methodology, disease, and setting, through exploring 'ethics in practice' within ethnographic research with middle-income young women living with HIV in Lusaka, Zambia.

'Procedural ethics', the process of institutional regulation of research ethics through ethical guidelines and oversight by research ethics committees (RECs), has offered important guidance for thinking about research ethics since the 1970s (Guillemin \& Gillam, 2004; Kerasidou \& Parker, 2014). The Association of Social Anthropologists of the UK and the Commonwealth (ASA) and the American Anthropological Association (AAA) have proposed core ethical principles to guide anthropological 
research across its various subfields and practical contexts. These principles are primarily oriented around the ethical principles of non-maleficence; informed consent; honesty and trust; respectful and fair relationships; privacy and avoiding undue intrusion; accessibility of results; confidentiality, anonymity and data protection (American Anthropological Association, 2012; ASA, 2011). Others have emphasised the balancing act needed between procedural research ethics and the importance of community involvement in ethnographic research (Nyambedha, 2008). Additional frameworks have also been developed to provide more guidance on navigating the ethical challenges deriving from researcher-participants relationships in ethnographic research and the power dynamics between different actors in research (Iphofen, 2015). It is acknowledged that some ethical dilemmas arising from the positionality of the ethnographic researcher may remain unresolved, despite best intentions and careful attempts to mitigate them (Huisman, 2008). Further, there has been growing awareness of the ethics of post-research obligations, including access to effective interventions for participants and their wider communities, particularly in LMICs (Nuffield, 2002).

However, there has been extensive debate about the relevance, scope and form of such 'procedural ethics', particularly within the field of anthropology and for ethnographic research (Hansjörg, 2017; Molyneux \& Geissler, 2008; Parker, 2007; 2012, ch 7). Heimer critiques the uniformity and universality of 'procedural ethics', which are usually formulated for American study sites and often do not translate well to other counties (2013). Qualitative, and especially ethnographic, research is characterised by 'fluidity and inductive uncertainty' (Mauthner, Birch, Jessop, \& Miller, 2002, p. 2) and what may have seemed 'morally uncomplicated at the outset 
may turn out to be fraught with difficulty once a project is underway' (Iphofen, 2015, p. 18). As a result, the requirement for researchers to practise 'personal moral reflexiveness and integrity' in ethnographic research is therefore heightened and the onus of continuous ethical mindfulness, arguably, weighs more heavily on ethnographic researchers than on RECs (Molyneux \& Geissler, 2008, p. 9).

Several scholars have stressed the value of thinking about ethics beyond the 'procedural' stage, and demonstrated the importance of reflecting critically on ethical guidelines and practice in order to enable more ethical research conduct. Kingori shows how the practice of ethics by frontline researchers is set within the parameters of institutional interpretations, but these are generally peripheral to researchers' faceto-face interactions with participants and their own ethical values and motivations (2013). Similarly, Aellah et al. highlight the ways in which the 'momentary pursuit of morally right actions in personal interactions with other humans' is 'complex and spontaneous' (2016, p. 13). This dimension of ethics in research has been termed 'ethics in practice', referring to 'the day-to-day ethical issues that arise in the doing of research' (Guillemin \& Gillam, 2004, p. 264). Applying this to ethnographic research, Jarvis illustrates the necessity of employing Aristotelian 'practical wisdom' when interpreting and contextualising international guidelines in cross-cultural settings (Jarvis, 2016). Researchers can exemplify such 'practical wisdom' by using practical judgment to do the right thing in the right way in a particular situation and context (Kinsella \& Pitman, 2012). Together, this growing body of literature suggests that in order to respond adequately to the specific and sometimes unique ethical challenges arising in the context of international research, ethnographic researchers should engage deliberately with 'ethics in practice' through on-going and critical reflexivity. 
However, literature detailing examples of employing such critical reflexivity in international research contexts is limited, despite its potential to ensure more ethical research practice, enrich the development of ethical guidelines and frameworks and enhance mutual understanding between ethnographic researchers and RECs.

Research around HIV has, historically, also presented a range of ethical issues, including questions around human rights, resource allocation, consent around testing, sexual morality, and individual responsibility (Heimer, 2013; Venter, Allais, \& Richter, 2014). The stigma surrounding HIV means that issues around privacy and confidentiality are especially important (Hlongwa, 2016). Madiega et al. describe how the repeated presence of researchers visiting households raised risks of inadvertently disclosing the HIV status of their participants (2013). This led to uncomfortable, yet necessary, decisions by research staff to assume alternative identities, including 'sister-in-law' or 'visitor', rather than 'HIV-researcher' to mitigate those risks (Madiega et al., 2013).

Much research in HIV has focused on lower-income groups. However, in some subSaharan countries, including Zambia and Tanzania, some middle- and upper-income groups have particularly high HIV prevalence (Central Statistical Office \& MoH., 2014; Long \& Deane, 2015; Parkhurst, 2010). Despite this group having a higher than average HIV prevalence, middle-income women are notably under-researched and relatively little is known about the factors that contribute to higher HIV prevalence among this population (Awusabo-Asare \& Annim, 2008; Long \& Deane, 2015). This ethnographic study thus aims to improve our understanding of the possible responses to HIV among middle-income young women so that more tailored and appropriate 
HIV prevention, treatment and care programs and policies can be developed in the future to address the needs of this population.

Drawing on a case study of ethnographic research with middle-income young women living with HIV in Zambia, this paper gives a reflexive account of how ethical issues are navigated in practice, when 'procedural ethics' alone are inadequate to provide guidance. We describe the ethical issues arising from the layered interaction of the population (young women), the disease under investigation (HIV), the method of study (ethnographic), and the setting (Zambia, a LMIC). Through this, we exemplify and advocate for deliberately moving such reflections on the 'ethics in practice' into the foreground of scholarly discussion within global public health to enhance understanding of the kinds of ethical challenges that ethnographic researchers do and should actively engage with during research. 


\section{Methods}

This study draws on ethnographic research, conducted by the first author (CMY), with seven young women living with HIV (aged 17-19 years) in Lusaka. The research took place over 12 months in 2017-2018, and aimed to understand the impact of HIV on the everyday lives of young women living with HIV, the results of which have been presented elsewhere (Mackworth-Young, Bond, \& Wringe, 2018). The analysis, on which this study is based, emerged as a product of the reflections of the researcher's engagement with the ethical aspects of the research before, during and after the study. In order to capture the ethnographic reflective voice, this paper uses the first person, referring to the first author when discussing data collection and fieldwork. All authors contributed to the interpretation of the data and writing of this manuscript.

The research was conducted as part of a PhD project based at Zambart (a Zambian research institution) and the London School of Hygiene and Tropical Medicine (LSHTM). Zambart is committed to applied public health research and for more than two decades has been implementing research projects in Zambia based on longstanding relationships with local communities, policy makers and implementers working in the HIV and TB response. The rationale for this $\mathrm{PhD}$ research grew out of previous studies conducted by Zambart with young women living with HIV (Mackworth-Young et al., 2017; Stangl et al., 2015). Further, the findings contributed to the design of further research studies including operational research that developed a support group intervention for young women living with HIV in Lusaka (Clay et al., 2018) and two randomised control trials with young people in Zambia, for a 
community-level delivery of sexual and reproductive health services and an HIV test and treat intervention (Shanaube et al., 2017) .

\section{Participants}

We were first in contact with the participants of this study in 2014, when we recruited them to participate in an exploratory qualitative study conducted in partnership with Zambart and the International Centre for Research on Women, when they were aged 15-16 years (Mackworth-Young et al., 2017). In this study, we had recruited 24 young women living with HIV from two health facilities in Lusaka, met with their parents or guardians to discuss parental informed written consent, and, alongside a small research team, conducted in-depth interviews and participatory workshops with the participants. The study ended in 2015 , but at their request, all participants were invited to participate in monthly support groups meetings for one year thereafter, until 2016, during which we sustained contact with them.

In 2017, we purposefully selected nine young women living with HIV from this original cohort to participate in the ethnographic study, from which this paper draws. They were selected based on being middle-income, defined as their parent or guardian having a formal job, and living in a more affluent area of Lusaka, where there is a lower population density and houses generally have a wall around them and their own supply of electricity and water. Due to the home-based, long-term and intimate nature of this ethnographic study, and the cultural context of close and inter-dependent familial relationships, we decided that it would be appropriate to involve both participants and their parents/guardians in the informed consent process. This was 
deemed culturally appropriate and was approved by the local Humanities Research Ethics Committee of the University of Zambia. The study protocol thus stated that both participant and parental/guardian consent would be necessary for participation, despite all but one of the participants being over the age of 18 at the start of the study. Out of the nine young women asked to participate, seven participated (Table 1). Two of the nine women selected did not participate due to their parents/ guardians not giving their consent, both due to family issues at home. All participants were provided with a referral sheet with a list of appropriate people and organisations that they could contact, including trained and experienced counsellors, and to whom they could be referred by the researcher if necessary.

Table 1. Participant characteristics at beginning of ethnographic study in 2017

\begin{tabular}{|c|c|c|c|c|c|c|}
\hline Participant* & Age & $\begin{array}{l}\text { Key family } \\
\text { member with } \\
\text { whom she } \\
\text { stays }\end{array}$ & $\begin{array}{l}\text { Orphan } \\
\text { status }\end{array}$ & $\begin{array}{l}\text { Mode of } \\
\text { HIV } \\
\text { acquisition }\end{array}$ & Education & $\begin{array}{l}\text { Year } \\
\text { started } \\
\text { ART }\end{array}$ \\
\hline Rose & 19 & $\begin{array}{l}\text { Father and } \\
\text { step-mother }\end{array}$ & $\begin{array}{l}\text { Single } \\
\text { orphan }\end{array}$ & MTCT** & $\begin{array}{l}\text { Completed grade } 12 ; \\
\text { studying to re-sit exams }\end{array}$ & 2010 \\
\hline Thandi & 18 & Mother & $\begin{array}{l}\text { Single } \\
\text { orphan }\end{array}$ & MTCT & Studying at College & 2012 \\
\hline Natasha & 18 & Aunt & $\begin{array}{l}\text { Double } \\
\text { orphan }\end{array}$ & MTCT & $\begin{array}{l}\text { Complete Grade 12, } \\
\text { applying for College }\end{array}$ & 2008 \\
\hline Rhoda & 19 & Mother & $\begin{array}{l}\text { Single } \\
\text { orphan }\end{array}$ & MTCT & $\begin{array}{l}\text { Completed Grade 12, } \\
\text { applying for College }\end{array}$ & 2005 \\
\hline Mavis & 19 & Grandparents & $\begin{array}{l}\text { Double } \\
\text { orphan }\end{array}$ & $\begin{array}{l}\text { Sexual } \\
\text { abuse }\end{array}$ & Completed Grade 12 & 2017 \\
\hline Mary & 17 & Mother and & Single & MTCT & Studying at College & 2014 \\
\hline
\end{tabular}




\begin{tabular}{|c|c|c|c|c|c|c|}
\hline & & Aunt & orphan & & & \\
\hline Sophie & 19 & Uncle & $\begin{array}{l}\text { Double } \\
\text { orphan }\end{array}$ & MTCT & $\begin{array}{l}\text { Completed Grade } 12, \\
\text { studying to re-sit exams }\end{array}$ & 2008 \\
\hline
\end{tabular}

\footnotetext{
*All names used are pseudonyms

** Mother to child transmission (MTCT)
}

Simultaneously to the ethnographic study on which this paper is based, at Zambart, in collaboration with the International Centre for Research on Women, we conducted an evaluation of a pilot support group intervention for young women living with HIV in Lusaka. The design of this intervention was based on requests and input from the young women in the previous qualitative study conducted in 2014-2015. Three of the young women who participated in the ethnographic study were asked to co-facilitate these support groups, alongside experienced counsellors.

At the beginning of the ethnographic study the participants' ages ranged from 17-19 years (Table 1). All participants were orphans (with only one or no parent surviving), and all except one considered themselves infected with HIV by mother to child transmission (MTCT). All of them were regularly attending HIV clinics and were on anti-retroviral therapy (ART). All participants were middle-income, Christian and had taken part in previous research and support groups. They lived across Lusaka, with some occasionally spending large amounts of time outside Lusaka with family or for college. All participants had finished school, although two were resitting their final school exams during the ethnography. Two were in college at the beginning of the ethnography, rising to four at the end.

\section{Data collection}


Over 12 months, I conducted participant observation, spending significant amounts of time with each of the seven participants in their respective homes, workplaces, colleges, recreational spaces, health facilities and churches, in dozens of locations across Lusaka. This was primarily with research participants, but also with others with whom participants interacted, including their families, friends, and boyfriends. With each participant I conducted an average of 20 observations (range 12-24), totalling 276 hours of participant observation. I spent time with participants at different times of day and days of the week to ensure a varied and detailed understanding of their everyday lives. I wrote up notes after each session with participants, covering the space of the observation, conversations and interactions with the participants and others, and reflexive thoughts about the observation, including any ethical challenges arising.

The study began and ended with two participatory workshops. The first participatory workshop aimed to discuss what the research would involve and to ask for participants' input into the research design. At this initial workshop participants were given materials (A3 coloured card, a range of magazines, newspapers and pens) and asked to create visual collages to represent themselves, what they liked, what they had experienced in the past, and what they wanted in the future. The last workshop aimed to close the research collectively with all participants, present initial findings, and seek their input into findings and on-going analysis. Both workshops were recorded through written notes. At about six months into the study, I gave participants diaries (with combination locks to enable privacy), and asked them to write about their daily activities and feelings. These diaries were returned to me to read, scan and transcribe 
after one month. The authors have critically reflected on the use, benefits and challenges of participatory research methods in a separate analysis (MackworthYoung, Wringe, et al., 2018).

Ethical clearance was obtained from the review boards of the University of Zambia Humanities Research Ethics Committee and the London School of Hygiene and Tropical Medicine.

\section{Data analysis}

The process of fieldwork was iterative, with cycles of data collection and analysis, and initial analysis informing subsequent data collection. 'Ethics in practice' emerged inductively as a key area of interest early on in data collection, building on an original focus on ethical issues that were considered during the design of the study, and later became a key focus in subsequent data collection. I deliberately and regularly reflected on the practical ethical challenges that arose during the course of the study and how these were navigated when writing the participant observation notes, as well as in multiple conversations with the co-authors, including a Zambian ethicist (MS). After the completion of data collection, all data relevant to 'ethics in practice' were manually coded and extracted. Data included field notes from participant observation sessions, workshop notes, transcripts of participants' diaries and the visual collages created by participants. Ethical issues that were either seen to be consistent across participants, or that were unusual or notable, were collated for thematic analysis.

\section{Reflexivity}


I conducted the data collection, and led data analysis for this paper, as part of my $\mathrm{PhD}$ research, in collaboration with the other authors. I had lived in Lusaka, Zambia since 2014, when I first started working for Zambart, conducting research with the cohort of young women, starting with an applied study of their transitions to adulthood, that led to the development of support groups for the same group, and until the end of this ethnographic study in 2018. Although I learnt to speak basic conversational Nyanja (the most commonly spoken language in Lusaka), the majority of data collection took place in English. Participants and their families and friends spoke English fluently, and much day-to-day interaction took place in English. However, some conversations between family members were missed due to the language barrier.

The relationship between myself, the researcher, and the participants formed a central aspect of the study. The long-term established institutional relationships between Zambart and the local community, as well as my prior connection with the participants had enabled the development of important trust and rapport with them (and, to some extent, their families), which was built upon during this ethnographic study. With an understanding of the co-produced nature of data generation and analysis, I was continuously reflexive about how my identity as a young white-British woman influenced the relationship that I had with participants and their families, as well as the data produced. My identity in part led to me being viewed as a trusted person by participants and their families, but also being a clearly visible outsider. Further, differences in age, power, wealth, and knowledge about research between the participants and me as the researcher led to inevitable power and relational dynamics. 
Reflecting on this relationship and how it influenced data collection forms the basis of some of the practical ethical challenges discussed in the results that follow. 


\section{Results}

We present results on the 'ethics in practice' encountered during this ethnographic study in five broad ethical themes. These include the perceived benefits of participation and how these changed over the course of the study; the negotiated relationship between the participants and myself as the researcher; protecting participants from harm by telling 'white lies' about the research; balancing the protection of participants' confidentiality with ownership and autonomy over their data; and lastly considerations about obligations following the end of the research.

\section{Perceived benefits of the research}

During the informed consent process, several participants and their parents or guardians initially questioned what the benefits of the research would be to participants. In a context of HIV programs, intervention and biomedical research, initially, some participants enquired whether the research would offer benefits that go beyond the obligations of ethnographic research, such as financial benefits to support college fees for the participants. During the informed consent process, I clarified that there were no direct benefits to the participants, including financial benefits to taking part in the study, although reimbursement was provided for transport costs to attend workshops, and food and drinks were provided at workshops and whenever participant observation took place in recreational spaces, such as cafés or restaurants.

Throughout the course of the research, participants' understanding of the benefits and value of participating in the research evolved. Participants increasingly expressed 
valuing non-material benefits, particularly the psycho-emotional support gained from their relationship with myself as the researcher. My position as a young woman and as an outsider enabled participants to open up about parts of their lives that they otherwise felt they could not talk about. One participant reflected on this benefit of the research, when reflecting on the study as a whole:

I told you everything that was going on my life, even things that I didn't tell my mum. Of course I tell my mum lots of things, but there are just some things that I can't tell her, and that I needed to talk to someone else about, and you were always there to listen. It was so nice for me to have someone I could feel I could tell everything to. I didn't know I had so much going on in my life until I had the chance to talk to you and tell you everything about it. (Thandi, participant observation)

Most of the participants expressed valuing the trusting, confidential and nonjudgmental relationship with myself as the researcher:

Can I tell you a secret? I don't know why I always feel like I can tell you all my secrets, but I just do. (Mavis, participant observation)

Many of the participants lacked someone who was able to take the time to listen actively, and they valued the fact that the research created a space for them within which they could reflect on their lives:

If you're talking to a friend, they always interrupt and tell me something about themselves, but you are a very good listener, and just listen to our stories. (Rose, workshop)

\section{Participant-researcher relationship}


Participants were curious to also learn about my life, and, as such, I, as the researcher often became the 'researched', as the participants in turn questioned me about my life, asking to look at photos on my phone, and asking about my home, work and family. I appeared in participant's photos on their phones, including with their friends and families. There was a clear desire from participants to understand about my life: 'tell me about your house, your husband, really everything about your life' (Rhoda, participant observation). To reciprocate the openness with which participants had approached the research, I felt it was important to share certain aspects about my life. In this way the enquiry became bi-directional, and the traditional boundaries between the 'researcher' and the 'researched' became blurred. Nonetheless, I constantly had to reassess when it was appropriate to allow the ambiguous boundaries between research and friendship to soften and when to draw the line in sharing about my life. For instance, although I visited participants' homes regularly, I declined when participants asked to visit my home, to ensure some boundaries over respective roles of researcher and participant remained.

Ethical issues emerged when the participants negotiated their relationship with me, as the researcher, to widen the scope of benefit they derived from participation, which was done in two ways. Firstly, while I emphasised my role as an observer, participants' frequently sought my advice, including asking opinions on which course to apply for at college, or whether to date particular individuals. The 'official ethics' of remaining an observer were questioned, particularly when participants confided that they had not told anyone else about their situation, and sought advice from me: 'I haven't spoken to anyone else about this. Just in the diary and to you.' (Mary, 
participant observation). My strategy in such cases, in order to limit the degree of intervention, was to use active listening, rather than give advice, including open questioning and reflecting questions back to the participant, and in this way help participants to talk through and reflect on problems, without offering direct advice.

Beyond advice, some participants asked me to intervene actively in their relationships. The participants' awareness of the power and relationship dynamics between us led to my position as a trusted person by both the participants and their families being requested in several instances to assist in family disputes. For example, one participant asked me:

I have a favour to ask you. Could you possibly call my sister and tell her that we met, you met with me, and that you saw where I am staying, that I am staying with a friend, and that I am living somewhere that's nice and safe. Will you tell her that, because she trusts you, and it'll sound better coming from you than from me. (Mavis, participant observation)

While I understood the importance to Mavis of restoring the difficult relationship with her sister, I could not gauge the implications of intervening in this complex relationship, and whether this would in fact serve the best interests of the participant. Additionally, the safety of Mavis' new home was uncertain, particularly as the coresiding father of her friend was an alcoholic, and so in this case the decision was to not intervene. This decision was made, in consultation with colleagues, including a Zambian ethicist (MS), with respect to upholding the primary principle to 'do no harm', commonly emphasised across ethics guidelines for anthropological research (American Anthropological Association, 2012; ASA, 2011). In this particular case, my active intervening may have resulted in unintended negative consequences for 
Mavis. However, I felt some 'moral residue' (Epstein \& Hamric, 2009), that I was unable to assist Mavis in this matter, given the generosity of participants in terms of opening up about their lives. I discussed my decision with Mavis, and emphasised that this kind of intervention was outside the scope of my role as the researcher, which she said she understood.

\section{Truth telling and 'white lies'}

The context of participants' very limited disclosure of their HIV status raised ethical considerations for the research. Being an outsider to the community, my repeated presence with participants was both outwardly and privately questioned. I discussed with all participants and their parents or guardians the risk that the research might expose participants to unintentional disclosure, during the informed consent process, the introductory workshop, and regularly throughout the research. In the introductory workshop, participants were asked to decide collectively how to describe the research to others who did not know their HIV status in a way that protected their HIV status and that of other participants. It was agreed that we would describe the research to others who did not know their HIV status as anthropological research looking at the everyday lives of young women in Lusaka, and to adapt this to the specific circumstances for each participant, based on their personal choices.

Therefore, when meeting friends and family who didn't know the participants' HIV status, I used whatever cover-up story the participants' felt was most appropriate in each circumstance. This led me to adopt a range of different identities, including 'friend', 'researcher on young women's lives', 'someone I met through the support 
groups', and even in one instance 'relative'. During the informed consent process, for some, it was the worry of unintentional disclosure through the research that was the biggest concern in participating: 'the only thing that worries me is her brother finding out about her status' (Rose's father, participant observation). Ironically, the research actually ended up being used as a cover-up story with this participant. When Rose's brother's wife discovered her ART and questioned her about it, put on the spot, Rose used participation in the research as the reason why she had ART, stating:

In the research I do workshops, where I have to show other people what the pills are, and how to take them. (Rose, participant observation)

In this case, the research was both a potential risk of unintentional disclosure, but also used as a convenient cover-up story.

The one time that I was directly questioned about whether the research was linked with HIV was by the father of a participant's friend, with whom she was living at the time. The participant, Mavis, had actively chosen not to disclose her HIV status to her friend or the father, based on her witnessing their negative reactions to discovering that their domestic worker was living with HIV. Mavis explained the research to her friend's father as being anthropological research with young women in Lusaka, without mentioning HIV. Unprompted, the father asked me directly whether the research was looking at HIV. Making an on-the-spot decision, I responded, saying:

This research does not focus on anything like that (HIV) but it's more broadly trying to understand how young people in Lusaka live their lives (Researcher, participant observation with Mavis). 
Given the fear of unintentional disclosure and the negative consequences reported by those who had experienced this, protecting confidentiality was seen to outweigh the importance of truthfulness to participants' relatives, friends or community members in all circumstances. Participants reported being so used to telling cover-up stories to protect their HIV status that the additional stories around the research were seen as 'not a big deal' (participatory workshop). They viewed it as essential, since they lived with 'poky' or 'nosy' people (participatory workshop), although they did express guilt and anxiety around telling lies everyday, particularly to people who were close to them. For me, telling such 'lies' proved uncomfortable and left some 'moral residue' (Epstein \& Hamric, 2009), despite being seen as essential to protecting participants.

\section{Confidentiality and data ownership}

Alongside the collection of their stories, participants produced material data during the research, through creating collages and writing diaries. The question of ownership of data and data use led to ethical tensions between giving participants autonomy over their data, and my role, as the researcher, in protecting participants from harm. One example of this was the practical decision around whether participants were given the choice to keep the material data (diaries and collages) that they created. In this example, the potential for harm included family or friends finding their collage or diary at home, possibly leading to unintentional and harmful disclosure of a private identity, such as their HIV status or secret relationships. While I engaged in conversations about the potential harms to ensure that participants could arrive at an informed decision, the decision was made to place the choice in the hands of the participants. This was with the understanding that the participants were in the best 
position to assess the potential harms and their likelihood in each particular situation. This led to different decisions being made by different participants. Some saw tangible benefits to keeping their data, including having an outlet or method to express themselves:

I really want to keep the diary. It's been the only place I can openly speak about all the difficulties these last few weeks. (Natasha, participant observation) I want to show it (the collage) to my friend. I just disclosed to her, and I want her to understand what I've been going through. (Sophie, participant observation) However, others felt the risk of keeping their data was too great, and preferred the responsibility of data storage to remain in the hands of the researcher.

I think it's best if you keep it (the collage). I don't have anywhere safe for it, and I worry if my roommates found it, that they would ask a lot of questions. (Mary, participant observation)

By providing participants with the choice, they were given the autonomy to weigh up the risks and benefits for their personal situation. However, the constraints within which this choice was being made must be noted. Many participants lived in spaces with extremely limited privacy, restricting their choice to keep their data. On the other hand, in the context of participants having relatively limited spending money, the diaries with a combination lock were seen to be desirable personal items to keep. In order to ensure that participants were free in choosing to keep the diary specifically for its content, rather than simply for the sake of owning a diary, they were also offered the option of being given a clean diary (without their written data). One participant took up this offer, as she was worried about her family reading sensitive 
things that she had written, but none were keen to lose this desirable item by simply leaving it with me.

\section{Obligations post-research}

Heightened by the longitudinal and in-depth nature of the research, and the resulting intimate relationships between the participants and myself, uncertainties around my obligations, as the researcher, towards the participants following the study posed further ethical questions. These included how the close and long-term relationship ought to be brought to a close. The participants expressed sadness at losing someone they were able to talk to and share worries, concerns, joys and aspirations with at the end of the research: 'who will I just be able to talk to about anything when you've gone?' (Thandi, participant observation). The decision was taken to place a workshop at the beginning and end of the study, which served a symbolic purpose of formally marking and signalling the boundaries of the otherwise informal structure of the study. The closing workshop depersonalised and communalised the ending of the relationships between the researcher and the participants, and offered the opportunity to strengthen the peer support and friendships that had developed between participants during the course of this and earlier studies in which they had participated. While continued contact between participants and me was not actively encouraged, I enabled some contact after the research through a social messaging platform, to gradually close the relationship and the support this provided.

Throughout the study, participatory methods were used, including participants' input into the study design in the introductory workshop, collage making and diary writing. 
This extended to the end of data collection: during the closing workshop, the participants were actively asked for their input into the interpretation and analysis of data, which fed into the iterative analysis of results around the main research question on understanding the impact of HIV on their lives. Beyond this, three of the participants of the ethnographic study had additionally been asked to co-facilitate support groups in a separate, but linked intervention evaluation. These young women were given additional training and experience in research and facilitation methods by the counsellors who facilitated the support groups, as well as payment for their cofacilitation role. Due to their long-term participation in and in-depth contributions to sequential research studies, this form of participant capacity building felt appropriate. Some of the young women were subsequently asked to facilitate other independent youth groups. However, despite these additional benefits to participants, I ended the research feeling some 'moral residue' (Epstein \& Hamric, 2009) at the fact that many of the everyday concerns of participants and their families, such as financial worries over paying for college fees, remained unaddressed, as they were considered outside the scope of the research. 


\section{Discussion}

Through identifying and exploring 'practical' ethical issues in this ethnographic study with young women living with HIV in Zambia, we provide a case study of critical ethical reflexivity in global health research. We highlight ethical tensions that arose from the interplay between studying a vulnerable population in a lower-middle income setting using ethnographic methods, and how these ethical issues were navigated. For researchers, we highlight the value of high levels of reflexivity throughout the research process for global health research, and we thus contribute to a small but important body of literature actively reflecting on 'ethics in practice' (for example Jarvis, 2016; Madiega et al., 2013; Mannell \& Guta, 2017). For those involved in 'procedural ethics', this paper suggests that RECs have an important role in gauging whether researchers have adequate ethics training and skills, and whether institutions have sufficient capacity and competence to critically engage with complex ethical problems as they inevitably arise in the context of their research. Using lessons from this study, we will now examine the relevant assumptions proposed by standard ethical guidelines, and suggest implications for future research practice and ethical guidelines.

Firstly, we demonstrate that participants' perception of the benefits of the research changed over the course of the study, with participants placing increasing emphasis on the value of psycho-emotional support provided through their relationship with the researcher. Further the study carved out designated space and time for the participants to engage in self-reflection, which may itself have served as psycho-emotional support. A number of participants specifically expressed enjoying this element of the 
research and valuing the activities associated with self-reflection, such as journaling. In contrast, considerations about the benefits of participation in research captured within standard ethical guidelines (for instance CIOMS, 2016) are largely based on clinical, financial or material gains to participants. Previous work has highlighted the support gap in meeting the emotional needs of young women living with HIV in many settings (Chandra-Mouli, Armstrong, Amin, \& Ferguson, 2015; Stangl et al., 2015), in particular an unmet need for well-run counselling and support group services (Li et al., 2017; Mupambireyi, Bernays, Bwakura-Dangarembizi, \& Cowan, 2014). This study reinforces this support gap in Zambia, which was highlighted by the value attributed by the young women to the relationship with the researcher, and their expressed desire to speak more openly to someone about HIV and other issues in their lives. In settings where there is such a gap in psycho-emotional support, we therefore argue that current conceptions of what constitutes benefits of research need to go beyond what is included in standard guidelines to consider potential psychoemotional benefits that ethnographic or other qualitative research may offer to participants.

Like others (Fichtner \& Trần, 2018; Finch, 1992; Mannell \& Guta, 2017), we highlight that in ethnographic studies, the enquiry can be bi-directional and the researcher's role involves continual negotiation. This recognition questions the applicability of objective and traditional role boundaries between the researcher and the researched for ethnographic research. We support Mannel and Guta's findings that this bi-directional questioning helped to ameliorate power relationships inherent in research encounters, but could sometimes present the researcher with uncomfortable 
choices, and so flexible boundaries are helpful to maintain roles as researcher and participants (2017).

In the context of research about a stigmatised disease with limited disclosure, we demonstrate the kind of moral tensions that may arise for researchers when having to balance personal moral principles of truthfulness against upholding professional confidentiality and protecting participants from harm. This is covered in more detail in a separate analysis from this study (Mackworth-Young, Bond, et al., 2018). Previous anthropological research has shown the need for data collectors to adopt untruthful identities to protect participants' HIV status (Madiega et al., 2013), and we concur with their findings around the 'moral residue' (Epstein \& Hamric, 2009) and discomfort felt by data collectors, who nonetheless understand the necessity to tell untruths about themselves, the research and the participants. Ethical guidelines rarely give researchers advice on how to navigate these ethical challenges, although some teaching materials have proposed relevant strategies. These include providing case studies that stimulate researchers to think through the ethics of truth telling and lying when conducting community-based research (Aellah et al., 2016; Guillemin \& Gillam, 2015). While many decisions inevitably must be made in context, having sensitive and flexible frameworks for such decision-making could offer important support for frontline researchers.

Several of the ethical issues identified in this study relate specifically to young people. In order to ensure that the measures established to protect young people from harm do not result in preventing their participation in research, young people's capacity for decision-making needs to be assessed within each particular context 
(Gibson, Stasiulis, Gutfreund, McDonald, \& Dade, 2011). Researchers need to be cognisant of the constraints within which these decisions are made, for instance limited privacy and spending money seen here, or limited autonomy of young people within Zambian society documented elsewhere (Simpson, 2009). However, we have shown that when given sufficient information, room for discussion, and autonomy for decisions, such as whether to keep the diaries and collages that participants created, the young women showed capacity to balance the risks and benefits, and demonstrate that they, not the researcher, were best placed to make those decisions. In this study young people also showed capacity for being integrally involved in the research process. This extended beyond ownership of data to giving input into the research design, analysis and interpretation through participatory workshops. This finding supports and extends current ethical guidance recommending establishment of young people's advisory groups (Nuffield, 2015) to enable more participatory and integrated involvement of young people in the research process (Iphofen, 2015).

Beyond participants' engagement in analysis and interpretation of data, we highlight the ethical challenges involved in bringing an intimate and longitudinal research study to a close. Recognising the 'emotional labour' of research (McGarrol, 2017), ending intimate participant-researcher relationships can raise ethical issues for the participants and the researcher, especially when the research, as in most cases, has been unable to meet all the needs of the participants (Aellah et al., 2016). Addressing the obligations to end research in the most ethical way is particularly challenging for ethnographic research, for which specific guidelines are often deficient (eg. American Anthropological Association, 2012) or vague (eg. ASA, 2011, section 1.8). In this study, establishing a structured and formal closing to an otherwise fluid study, 
through the closing workshop, helped to depersonalise and communalise the end of the research and the participant-researcher relationship. Despite this, the ending of the relationship was not clear-cut, and continued contact on a social messaging platform over several weeks was considered appropriate to avoid an abrupt end to the intimate participant-researcher relationship, thus continuing the 'emotional labour' of the research beyond the official end of the study (McGarrol, 2017).

Research ethics guidelines have increasingly highlighted the need for global health researchers to consider post-research obligations, including capacity-building obligations towards researchers or health-care personnel (CIOMS, 2016). By involving participants as peer facilitators in a separate, but linked, support group intervention study, we support and extend CIOMS guidelines by advocating for the importance of including participants themselves in capacity building efforts, where appropriate and feasible.

Global health researchers need to be better supported and enabled to reflect actively on 'practical' ethical tensions, which they inevitably face throughout the research process, as this has the potential to contribute to the improvement of future research ethics guidelines and ethical research practice. This paper also suggests that 'procedural ethics' can play an important role in supporting ethnographers to go to the field well equipped. While this paper highlights the limits to what RECs can do to resolve the fluid, unpredictable, spontaneous micro-level ethical issues that arise in ethnographic research, we argue that RECs play a vital role in gauging whether a researcher or research institution has the skill and capacity to use 'practical wisdom' and engage with complex ethical problems as they inevitably arise in the context of 
ethnographic research. Specifically, when deliberation about approving such studies, RECs should assess whether the planning of a study involved meaningful consultations with local communities and institutions and the extent to which the researcher will be both supported by and embedded within a local research institution. This is important so that researchers will be able to reflect on and navigate ethical issues as they arise in real time, such as through regular discussions, mentorship, supervision sessions, or ethics clinics. Therefore, RECs should be attentive to a proposal's ability to demonstrate that the researcher has thought through the strategies they will employ and the local support structures they will draw on when having to meet inevitable unforeseen ethical challenges in field.

This paper adds an important case study of ethical reflexivity in a specific context of overlapping vulnerabilities of population, disease, setting and method, which suggests ways of understanding how 'ethically important moments' can be navigated in practice (Guillemin \& Gillam, 2004). In this time of heightened ethical guidelines and restrictions on research conduct, deliberately focusing on the 'ethics in practice' in this way helps navigate the ethical ambiguity of everyday research encounters. 


\section{Acknowledgements}

Our biggest thanks go to the young women who participated in the study, contributing their time, energy and stories to the research. We also thank the clinic staff and volunteers who assisted with the initial recruitment of participants. Many thanks also to Michael Parker for kindly reading a draft of the manuscript and for his comments. We also thank Stephanie Johnson for helpful discussions about autonomy and informed consent and Ruth Horn for providing useful references. This research was funded by the Economic and Social Research Council.

\section{Declaration of Conflicting Interests}

The authors declare that there is no conflict of interest. 


\section{References}

Aellah, G., Chantler, T., \& Geissler, P. W. (2016). Global Health Research in an Unequal World: Ethics case studies from Africa. Retrieved from Oxfordshire,

UK.: https://www.ncbi.nlm.nih.gov/books/NBK458764/pdf/Bookshelf NBK4 58764.pdf

American Anthropological Association. (2012). Principles of Professional http://ethics.americananthro.org/category/statement/

ASA. (2011). Ethical Guidelines for good research practice. Retrieved from https://www.theasa.org/downloads/ASA ethics guidelines 2011.pdf

Awusabo-Asare, K., \& Annim, S. K. (2008). Wealth status and risky sexual behaviour in Ghana and Kenya. Appl Health Econ Health Policy, 6(1), $27-$ 39. doi:10.2165/00148365-200806010-00003

Central Statistical Office, \& MoH. (2014). Zambia Demographic and Health Survey 2013-14. Retrieved from Rockville, Maryland, USA: https://www.dhsprogram.com/pubs/pdf/fr304/fr304.pdf

Chandra-Mouli, V., Armstrong, A., Amin, A., \& Ferguson, J. (2015). A pressing need to respond to the needs and sexual and reproductive health problems of adolescent girls living with HIV in low- and middle-income countries. Journal of the International AIDS Society, 18(Suppl 5), 20297. doi:10.7448/ias.18.6.20297

CIOMS. (2016). International Ethical Guidelines for Health-related Research Involving Humans. Retrieved from Geneva: https://cioms.ch/wpcontent/uploads/2017/01/WEB-CIOMS-EthicalGuidelines.pdf

Clay, S., Chonta, M., Chiiya, C., Mackworth-Young, C., Bond, V., \& Stangl, A. (2018). Tikambisane 'Let's talk to each other': a 6-session support group curriculum for adolescent girls living with HIV in Zambia. Retrieved from Washington, DC.: https://www.icrw.org/wpcontent/uploads/2018/09/ICRW Tikambisane Curriculum v7.pdf

Epstein, E. G., \& Hamric, A. B. (2009). Moral distress, moral residue, and the crescendo effect. The Journal of clinical ethics, 20(4), 330-342.

Fichtner, S., \& Trần, H. M. (2018). Ethical Ambivalences in Research With Children Living in Accommodation Centers for Refugees. Forum: Qualitative Social Research, 19(3). doi:10.17169/fqs-19.3.3150

Finch, J. (1992). Ethics and Politics of Interviewing Women. In M. Hammersley (Ed.), Social Research: Philosophy, Politics and Practice. London: Sage Publications Ltd.

Gibson, B. E., Stasiulis, E., Gutfreund, S., McDonald, M., \& Dade, L. (2011). Assessment of children's capacity to consent for research: a descriptive qualitative study of researchers' practices. Journal of Medical Ethics, 37(8), 504-509. doi:10.1136/jme.2010.040097

Guillemin, M., \& Gillam, L. (2004). Ethics, Reflexivity, and "Ethically Important Moments" in Research. Qualitative Inquiry, 10(2), 261-280. doi:10.1177/1077800403262360

Guillemin, M., \& Gillam, L. (2015). Emotions, narratives, and ethical mindfulness. Academic 
Hansjörg, D. (2017). Ethics, Epistemology and Ethnography: The Need for an Anthropological Debate on Ethical Review Processes in Germany. Sociologus., 67(2), 191-208. doi:10.3790/soc.67.2.191

Heimer, C. A. (2013). 'Wicked' ethics: Compliance work and the practice of ethics in HIV research. Social Science and Medicine, 98, 371-378. doi:10.1016/j.socscimed.2012.10.030

Hlongwa, P. (2016). Current ethical issues in HIV/AIDS research and HIV/AIDS care. Oral Diseases, 22 Suppl 1, 61-65. doi:10.1111/odi.12391

Huisman, K. (2008). “Does This Mean You're Not Going to Come Visit Me Anymore?": An Inquiry into an Ethics of Reciprocity and Positionality in Feminist Ethnographic Research. Sociological Inquiry, 78(3), 372-396. doi:doi:10.1111/j.1475-682X.2008.00244.x

Iphofen, R. (2015). Research Ethics in Ethnography/Anthropology Retrieved from http://ec.europa.eu/research/participants/data/ref/h2020/other/hi/et hics-guide-ethnog-anthrop en.pdf

Iphofen, R., \& Tolich, M. (2018). Foundational Issues in Qualitative Research. In R. Iphofen \& M. Tolich (Eds.), The Sage handbook of qualitative research ethics (pp. 1-18). London: Sage.

Jarvis, K. (2016). Dilemmas in international research and the value of practical wisdom. Developing World Bioethics., 17(1), 50-58. doi:10.1111/dewb.12121

Kerasidou, A., \& Parker, M. (2014). Does science need bioethicists? Ethics and science collaboration in biomedical research. Research Ethics., 10(4), 214226. doi:10.1177/1747016114554252

Kingori, P. (2013). Experiencing everyday ethics in context: Frontline data collectors perspectives and practices of bioethics. Social Science and Medicine, 98, 361-370. doi:10.1016/j.socscimed.2013.10.013

Kinsella, E. A., \& Pitman, A. (2012). Phronesis as Professional Knowledge. Rotterdam, Boston, Taipei: Sense Publishers.

Li, X., Harrison, S. E., Fairchild, A. J., Chi, P., Zhao, J., \& Zhao, G. (2017). A randomized controlled trial of a resilience-based intervention on psychosocial well-being of children affected by HIV/AIDS: Effects at 6and 12-month follow-up. Social Science and Medicine, 190, 256-264. doi:10.1016/j.socscimed.2017.02.007

Long, D., \& Deane, K. (2015). Wealthy and healthy? New evidence on the relationship between wealth and HIV vulnerability in Tanzania. Review of African Political Economy, 42(145), 376-393. doi:10.1080/03056244.2015.1064817

Mackworth-Young, C., Bond, V., \& Wringe, A. (2018). Everyday 'lies', hiding and secrecy: Ethnographic study exploring strategies adopted by young women living with HIV in urban Zambia to protect their identity. Paper presented at the Association for the Social Sciences and Humanities in HIV (ASSHH), Amsterdam, Netherlands.

Mackworth-Young, C., Bond, V., Wringe, A., Konayuma, K., Clay, S., Chiiya, C., . . . Stangl, A. (2017). "My mother told me that I should not": A qualitative study exploring the restrictions placed on adolescent girls living with HIV in Zambia. Journal International AIDS Society, 20, e25035. doi:10.1002/jia2.25035 
Mackworth-Young, C., Wringe, A., Clay, S., Chonta, M., Chiiya, C., Konayuma, K., . . . Bond, V. (2018). Critical reflections on the use of repeated collages to understand the experiences of young women living with HIV in urban Zambia. Paper presented at the International AIDS Conference, Amsterdam, Netherlands.

Madiega, P. A., Jones, G., Prince, R. J., \& Geissler, P. W. (2013). 'She's my sister-inlaw, my visitor, my friend' -- challenges of staff identity in home follow-up in an HIV trial in Western Kenya. Developing World Bioethics., 13(1), 2129. doi:10.1111/dewb.12019

Mannell, J., \& Guta, A. (2017). The ethics of researching intimate partner violence in global health: a case study from global health research. Global public health, 13(8).

Mauthner, M., Birch, M., Jessop, J., \& Miller, T. (2002). Ethics in Qualitative Research. London: SAGE Publications Ltd.

McGarrol, S. (2017). The emotional challenges of conducting in - depth research into significant health issues in health geography: reflections on emotional labour, fieldwork and life course. Area published by John Wiley \& Sons Ltd on behalf of Royal Geographical Society, 49(4), 436-442. doi:10.1111/area.12347

Molyneux, S., \& Geissler, P. W. (2008). Ethics and the ethnography of medical research in Africa. Social Science and Medicine, 67(5), 685-695. doi:10.1016/j.socscimed.2008.02.023

Mupambireyi, Z., Bernays, S., Bwakura-Dangarembizi, M., \& Cowan, F. M. (2014). "I don't feel shy because I will be among others who are just like me...": The role of support groups for children perinatally infected with HIV in Zimbabwe. Children and Youth Services Review, 45, 106-113. doi:10.1016/j.childyouth.2014.03.026

Nuffield. (2002). The ethics of research related to healthcare in developing countries. Retrieved from London, UK: http://nuffieldbioethics.org/wpcontent/uploads/2014/07/Ethics-of-research-related-to-healthcare-indeveloping-countries-I.pdf

Nuffield. (2015). Children and clinical research: ethical issues. Retrieved from London, UK: http://nuffieldbioethics.org/wp-content/uploads/Childrenand-clinical-research-full-report.pdf

Nyambedha, E. O. (2008). Ethical dilemmas of social science research on AIDS and orphanhood in Western Kenya. Social science \& medicine (1982), 67(5), 771-779. doi:10.1016/j.socscimed.2008.02.024

Office for Human Research Protections. (2018). Retrieved from https://www.hhs.gov/ohrp/

Parker, M. (2007). Ethnography/ethics. Social Science and Medicine, 65(11), 2248-2259. doi:10.1016/j.socscimed.2007.08.003

Parker, M. (2012). Ethical Problems and Genetics Practice. Cambridge: Cambridge University Press.

Parkhurst, J. O. (2010). Understanding the correlations between wealth, poverty and human immunodeficiency virus infection in African countries. Bulletin of the World Health Organization, 88(7), 519-526. doi:10.2471/blt.09.070185

Shanaube, K., Schaap, A., Chaila, M. J., Floyd, S., Mackworth-Young, C., Hoddinott, G., ... Ayles, H. (2017). Community intervention improves knowledge of 
HIV status of adolescents in Zambia: findings from HPTN 071-PopART for youth study. AIDS, 31 Suppl 3, S221-s232. doi:10.1097/qad.0000000000001530

Simpson, A. (2009). Boys to Men in the Shadow of AIDS: Masculinities and HIV Risk in Zambia. US: Palgrave Macmillan US.

Stangl, A., Bond, V., Mackworth-Young, C. R. S., Sievwright, K., Singh, D., Clay, S., ... Konayuma, K. (2015). Transitioning to a healthy adulthood: Lessons learned from adolescent girls living with HIV in urban Zambia. Retrieved from Lusaka:

Venter, F., Allais, L., \& Richter, M. (2014). Exposure ethics: does HIV preexposure prophylaxis raise ethical problems for the health care provider and policy maker? Bioethics, 28(6), 269-274. doi:10.1111/bioe.12021 